\title{
Beta-carotene Inhibits Atherosclerosis in Hypercholesterolemic Rabbits
}

\author{
Aviv Shaish, * Alan Daugherty, * Finbarr O’Sullivan," Gustav Schonfeld, * and Jay W. Heinecke *\$ \\ Departments of * Medicine, ${ }^{\ddagger}$ Biochemistry and Molecular Biophysics, and ${ }^{\S}$ Molecular Biology and Pharmacology, Washington \\ University School of Medicine, St. Louis, Missouri 63110; and "Department of Statistics, University of Washington, Seattle, \\ Washington 98195
}

\begin{abstract}
Oxidatively damaged LDL may be of central importance in atherogenesis. Epidemiological evidence suggests that high dietary intakes of $\beta$-carotene and vitamin $E$ decrease the risk for atherosclerotic vascular disease, raising the possibility that lipid-soluble antioxidants slow vascular disease by protecting LDL from oxidation. To test this hypothesis, we fed male New Zealand White rabbits a high-cholesterol diet or the same diet supplemented with either $1 \%$ probucol, $0.01 \%$ vitamin $\mathbf{E}, 0.01 \%$ all-trans $\beta$-carotene, or $0.01 \%$ 9cis $\beta$-carotene; then we assessed both the susceptibility of LDL to oxidation ex vivo and the extent of aortic atherosclerosis. As in earlier studies, probucol protected LDL from oxidation and inhibited lesion formation. In contrast, vitamin $E$ modestly inhibited LDL oxidation but did not prevent atherosclerosis. While $\beta$-carotene had no effect on LDL oxidation ex vivo, the all-trans isomer inhibited lesion formation to the same degree as probucol. Moreover, all-trans $\beta$ carotene was undetectable in LDL isolated from rabbits fed the compound, although tissue levels of retinyl palmitate were increased. The effect of all-trans $\beta$-carotene on atherogenesis can thus be separated from the resistance of $L D L$ to oxidation, indicating that other mechanisms may account for the ability of this compound to prevent vascular disease. Our results suggest that metabolites derived from all-trans $\beta$-carotene inhibit atherosclerosis in hypercholesterolemic rabbits, possibly via stereospecific interactions with retinoic acid receptors in the artery wall. (J. Clin. Invest. 1995. 96:2075-2082.) Key words: retinoids • vitamin $E \cdot$ antioxidant $\cdot$ lipid peroxidation $\cdot$ hypercholesterolemia
\end{abstract}

\section{Introduction}

Epidemiological studies have shown that a high intake of $\beta$ carotene and dietary supplements of vitamin $E$ are associated with a decreased risk for coronary artery disease $(1-3)$. One

Address correspondence to Jay W. Heinecke, Division of Atherosclerosis, Nutrition and Lipid Research, Box 8046, 660 South Euclid Avenue, St. Louis, MO 63110. Phone: 314-362-6923; FAX: 314-362-3513; Email: heinecke@visar.wustl.edu

Received for publication 26 January 1995 and accepted in revised form 20 July 1995.

\section{J. Clin. Invest.}

(C) The American Society for Clinical Investigation, Inc.

0021-9738/95/10/2075/08 \$2.00

Volume 96, October 1995, 2075-2082 explanation might be that lipid-soluble antioxidants protect LDL, the principal carrier of plasma $\beta$-carotene and vitamin $\mathrm{E}$ in humans $(4)$, from oxidation $(5,6)$. Elevated levels of LDL are a major risk factor for atherosclerosis, but several lines of evidence point to oxidatively damaged LDL as the atherogenic agent (7-9). First, oxidized LDL exerts numerous potentially atherogenic effects in vitro (7-11). Second, lipoprotein-like particles that appear to have been oxidatively damaged have been isolated from atherosclerotic tissue $(12,13)$, and proteinbound lipid oxidation products have been detected immunohistochemically in animal atherosclerotic lesions (14). Finally, chemically unrelated antioxidants slow lesion formation in LDL receptor-deficient rabbits $(5,6,15,16)$, and in cholesterol-fed rabbits (17) and primates (18), implicating oxidized lipoproteins in the pathogenesis of vascular disease in hypercholesterolemic animals.

Most studies with antioxidants have used probucol $(5,6$, 18), a lipid-soluble phenol that is carried by LDL in vivo and inhibits LDL lipid peroxidation in vitro (19). These properties suggest that antioxidants block atherosclerosis by protecting LDL from oxidation. Studies with two other lipid-soluble antioxidants, $N, N^{\prime}$-diphenyl-phenylenediamine (17) and butylated hydroxytoluene (15), support this hypothesis. Both compounds protect LDL from oxidation and slow the progression of vascular disease in hypercholesterolemic rabbits. In contrast, a structural analogue of probucol, bis(3,5-di-tert-butyl-4-hydroxyphenylether)propane, failed to prevent atherosclerosis in rabbits, even though it was a potent inhibitor of LDL oxidation in vitro (20). Plasma levels of the analogue and probucol were similar, but LDL isolated from animals treated with the analogue was oxidized more easily than LDL isolated from probucol-treated animals, leading to the suggestion that LDL must reach a threshold of resistance to oxidation to interrupt the atherogenic process (20). Alternatively, probucol might exert other antiatherogenic effects $(21,22)$.

$\beta$-carotene rapidly scavenges reactive oxygen intermediates $(23,24)$ but its ability to inhibit LDL oxidation in vitro is controversial (25-28). Whether $\beta$-carotene might prevent atherosclerosis in hypercholesterolemic animals has not previously been explored. Vitamin E can be a potent inhibitor of coppercatalyzed LDL oxidation (29), though under certain in vitro conditions this compound promotes LDL oxidation (30). Observational and interventional studies in humans $(2,3,31)$ and animals (reviewed in references 32 and 33 ) on the antiatherogenic effects of dietary vitamin $\mathrm{E}$ have yielded conflicting results.

Collectively, these results suggest that synthetic lipid-soluble antioxidants prevent atherosclerosis in hypercholesterolemic animals, and that a high dietary intake of natural antioxidants is 
associated with a decreased risk of vascular disease in humans. However, it remains to be determined whether antioxidants inhibit atherosclerosis by accumulating in LDL and protecting it from oxidation or whether other mechanisms might be involved. To investigate this issue further, we supplemented the diet of hypercholesterolemic rabbits with several structurally unrelated antioxidants, and then examined both the sensitivity of LDL to oxidation ex vivo and the extent of atherosclerotic lesion formation. We found that all-trans $\beta$-carotene significantly reduces the extent of atherosclerotic lesions without altering the susceptibility of LDL to oxidation. The susceptibility of LDL to oxidation can thus be dissociated from the extent of aortic atherosclerosis in hypercholesterolemic rabbits, suggesting that other mechanisms may be involved in the prevention of atherosclerosis by $\beta$-carotene.

\section{Methods}

Animals and diets. We used five groups of three male New Zealand White rabbits in the first set of experiments and five groups of eight in the second set, making a total of 55 rabbits. The control animals (11 animals) ate standard laboratory rabbit diet (Ralston Purina Co., St. Louis, MO) for $2 \mathrm{wk}$, and then to induce atherosclerosis, were fed standard diet supplemented with $0.5 \%$ (wt/wt) cholesterol (Ralston Test Diets, Richmond, IN) for 11 wk. The other groups of rabbits (each 11 animals) received supplements of antioxidants with both the standard and cholesterol-enriched diets. The probucol diets contained the high concentration of antioxidant $(5,6,17,20)$ used in most previous studies ( $1 \%$ [wt/wt] probucol $\left(4,4^{\prime}\right.$ - (isopropylidenedithio) bis [2,6-di-tert-butyl-phenol]); a gift from Marion Merrell Dow Research Institute, Kansas City, MO). The vitamin $\mathrm{E}$ and $\beta$-carotene were fed to the animals at 100 -fold lower levels; the vitamin E diets contained $0.01 \%$ racemic $\alpha$ tocopherol (Sigma Chemical Co., St. Louis, MO), the all-trans $\beta$-carotene diets contained $0.01 \%$ all-trans $\beta$-carotene (Sigma Chemical Co.), and the 9 -cis $\beta$-carotene diets contained $0.01 \%$ 9-cis $\beta$-carotene ( $>70 \%$ pure; isolated from the salt-tolerant alga Dunaliella bardawil (34); a gift from N.B.T. Company, Eilat, Israel). The animals (mean initial weight $2.7 \mathrm{~kg}$ ) were fed ad lib. (mean food intake 120 grams/ d) and mean body weight increased to the same extent in all groups during the 13 wk of the study. The Washington University Animal Studies Committee (St. Louis, MO) approved all procedures.

To avoid affecting the rate of cholesterol autoxidation in the diet, the antioxidants were dissolved in hexane and added to aliquots of diet (20\% of the final mixture) and dried under vacuum. The antioxidantenriched diet was then mixed with the rest of the diet and kept under vacuum for $3 \mathrm{~d}$ to remove any residual hexane. Control diet was sprayed with hexane alone. Diets were stored in the dark at $-20^{\circ} \mathrm{C}$ to prevent oxidation of cholesterol and antioxidants.

Atherosclerotic lesion evaluation. The percentage of aortic intimal area covered by atherosclerotic lesions was characterized as described (35). Animals were killed by overdosing with pentobarbital (120 mg/ $\mathrm{kg}$ ), then aortae were dissected free rapidly from the ascending arch to the ileal bifurcation and washed with ice-cold buffer A (PBS containing $200 \mu \mathrm{M}$ diethylenetriamine pentaacetic acid and $100 \mu \mathrm{M}$ butylated hydroxytoluene). The vessels were opened longitudinally, pinned flat on a wax bed immersed in ice-cold buffer A, photographed, and then stored at $-80^{\circ} \mathrm{C}$ until analysis. The intimal area covered with atherosclerotic lesions and the total aortic area were determined from digitized photographs by two observers (one blinded to the study design) using a Numonics model 2210 tablet (Numonics Corp., Lansdale, PA) and SigmaScan (Jandel Scientific, San Rafael, CA).

Antioxidant concentrations in plasma, liver, and aorta. The method of Shaish et al. (36) was modified to determine $\alpha$-tocopherol, $\beta$-carotene, and probucol levels in plasma, lipoproteins, and tissues. All procedures were carried out under dim light and on ice to prevent degradation of antioxidants. Samples ( $\sim 1$ gram) were extracted with $2 \mathrm{ml}$ of ethanol containing $10 \mu \mathrm{M}$ butylated hydroxytoluene. After the addition of $2 \mathrm{ml}$ $\mathrm{H}_{2} \mathrm{O}$ and $5 \mathrm{ml}$ hexane, the sample was mixed thoroughly and centrifuged for $5 \mathrm{~min}$ at $1,000 \mathrm{~g}$ to induce phase separation. An aliquot of the hexane layer was removed, dried under a stream of $\mathrm{N}_{2}$ and redissolved in $0.4 \mathrm{ml} \mathrm{CH}_{2} \mathrm{Cl}_{2}$. Antioxidants were subjected to reverse phase HPLC analysis on a Vydac C18 column (201TP-54, $250 \times 5 \mathrm{~mm}, 5-\mu \mathrm{m}$ particle size; Vydac, Hesperia, CA) with methanol/water (99:1; vol/vol) as the mobile phase at a flow rate of $1 \mathrm{ml} / \mathrm{min}$ (36). Probucol, $\beta$-carotene, and $\alpha$-tocopherol were detected by monitoring their absorbances at 240 , 450 , and $295 \mathrm{~nm}$, respectively, and by comparison with the retention times of authentic standards. Results are expressed as nanomoles antioxidant per gram wet weight of tissue.

Oxidation of $L D L$. Lipoproteins were isolated from rabbit plasma by sequential ultracentrifugation (35) and extensively dialyzed versus PBS at $4^{\circ} \mathrm{C}$ under $\mathrm{N}_{2}$. Oxidation reactions were carried out by exposing LDL $(\mathrm{d}=1.019-1.063 \mathrm{grams} / \mathrm{ml})$ to the azo radical generator $2,2^{\prime}$ azobis-(2-amidino propane hydrochloride)(AAPH) ${ }^{1}$ at $37^{\circ} \mathrm{C}$ in buffer B ( $150 \mathrm{mM} \mathrm{NaCl}, 200 \mu \mathrm{M}$ diethylenetriamine pentaacetic acid, $20 \mathrm{mM}$ sodium phosphate, $\mathrm{pH} 7.4$ ). The reaction mixture contained $0.1 \mathrm{mg} / \mathrm{ml}$ LDL protein and $1 \mathrm{mM}$ AAPH. Lipid peroxidation was monitored by the increase in absorbance at $234 \mathrm{~nm}$, which measures the formation of conjugated dienes in oxidized polyunsaturated fatty acids $\left(\epsilon=3 \times 10^{4}\right.$ $\mathbf{M}^{-1} \mathrm{~cm}^{-1}$; reference 37 ). The lag phase was determined graphically from the progress curve of lipid peroxidation as described (37). After a 4-h incubation, LDL lipid peroxides were determined as thiobarbituric acid-reacting substances (38) and cholesteryl ester hydroperoxides (39). Cholesteryl ester hydroperoxides were detected by absorbance at $234 \mathrm{~nm}$ after HPLC separation on a reverse phase column (ODS Ultrasphere, $250 \mathrm{~mm} \times 4.6 \mathrm{~mm}$, particle size $5 \mu \mathrm{m}$; Beckman Instruments, Inc., Fullerton, CA). The mobile phase was acetonitrile/2-propa$\mathrm{nol} / \mathrm{H}_{2} \mathrm{O}(44: 54: 2 ; \mathrm{vol} / \mathrm{vol} / \mathrm{vol})$ at a flow rate of $1 \mathrm{ml} / \mathrm{min}$ (39). Plasma concentrations of triglycerides, cholesteryl ester, and free cholesterol were determined enzymatically (Wako Chemical Co., Richmond, VA).

Statistical analyses. All values are reported as mean \pm SE. The strength of the statistical differences between pairs of groups were evaluated using the Mann-Whitney test (40). The Mann-Whitney approach was used because of its robustness to departures from assumptions of Gaussian statistics. A multiple comparisons analysis was carried out to evaluate the magnitude of the percent differences of aortic atherosclerosis between the mean responses in the treatment groups and the control group (40). Because the sample estimates of percent differences between the mean response in the control and treated groups are nonlinear functions of the data, simultaneous confidence regions were generated by the Tukey approach (40) with bootstrap methodology (41) being used to obtain the relevant distributions. $P$ values $\leq 0.05$ were considered significant.

\section{Results}

Control animals were fed standard diet for 2 wk followed by $11 \mathrm{wk}$ of standard diet supplemented with $0.5 \%$ cholesterol to induce atherosclerosis. The other groups of animals received supplements of antioxidants with both the standard and cholesterol-enriched diets. We used the same high level of dietary probucol, $1 \%$ of the diet by weight, that previous studies have shown inhibits atherosclerosis in hypercholesterolemic rabbits $(5,6,20,22,35)$. Vitamin $\mathrm{E}$ and $\beta$-carotene were fed to the animals at 100 -fold lower levels which corresponds to a daily intake of $\sim 3.5 \mathrm{mg} / \mathrm{kg}$ body weight. The intake of supplemental antioxidants in human trials has ranged from 0.3 to $20 \mathrm{mg} / \mathrm{kg}$ per day $(24,26,27,31)$.

Plasma lipid and lipoprotein levels. After the first 2 wk of

1. Abbreviation used in this paper: AAPH, 2,2'-azobis-(2-amidino propane hydrochloride). 
Table I. Plasma Cholesterol Concentrations in Control and Antioxidant-treated Rabbits

\begin{tabular}{llccl}
\hline & \multicolumn{4}{c}{ High cholesterol diet } \\
\cline { 2 - 5 } \multicolumn{1}{c}{ Group* } & $0 \mathrm{wk}$ & $4 \mathrm{wk}$ & $6 \mathrm{wk}$ & $8 \mathrm{wk}$ \\
\hline & \multicolumn{4}{c}{ Plasma cholesterol (mg/dl) } \\
Control & $49 \pm 4$ & $821 \pm 79$ & $1320 \pm 180$ & $1318 \pm 173$ \\
Probucol & $35 \pm 2^{\ddagger}$ & $670 \pm 64$ & $962 \pm 71^{5}$ & $1046 \pm 70$ \\
All-trans $\beta$-carotene & $49 \pm 3$ & $745 \pm 99$ & $1230 \pm 206$ & $1428 \pm 116$ \\
9-cis $\beta$-carotene & $55 \pm 3$ & $808 \pm 62$ & $1410 \pm 123$ & $1514 \pm 113$ \\
Vitamin E & $53 \pm 6$ & $903 \pm 52$ & $1560 \pm 120$ & $1372 \pm 99$ \\
\hline
\end{tabular}

The animals ate standard diet supplemented with the indicated antioxidant for 2 wk followed by 11 wk of standard diet supplemented with $0.5 \%$ cholesterol and the indicated antioxidant. Control animals received the standard and high cholesterol diets alone. Probucol-fed animals received the diets supplemented with $1 \%$ probucol (wt/wt). Vitamin $\mathrm{E}$ and $\beta$-carotene-fed animals received the diets supplemented with $0.01 \%$ antioxidant. Plasma cholesterol concentrations were determined enzymatically as described in Methods. Plasma cholesterol level of the rabbits upon entry into the study was $49 \pm 3 \mathrm{mg} / \mathrm{dl}$. Results represent the mean \pm SEM. ${ }^{*}$ Eight animals per group; ${ }^{\ddagger} P<0.01$ compared to control group; ${ }^{8} P<0.05$ compared to control group.

standard diets, plasma cholesterol concentrations were similar in all groups of rabbits except those that received supplementary probucol (Table I), where cholesterol was reduced significantly $(P<0.01)$. Large increases in plasma cholesterol concentrations were seen in the rabbits in each of the groups subsequently fed a high cholesterol diet (Table I). The probucol-treated group showed a trend towards lower cholesterol, but this was significant only at $6 \mathrm{wk}$. The other antioxidants failed to significantly alter plasma levels of cholesterol or triglycerides. There were no significant differences between the control group and the other groups in the plasma LDL, VLDL, and HDL cholesterol levels after $8 \mathrm{wk}$ of the high cholesterol diet (data not shown).

Effect of antioxidants on aortic atherosclerosis. A multiple comparisons analysis revealed that both the probucol and alltrans $\beta$-carotene-fed rabbits had significantly less $(P=0.039$ and 0.036 , respectively) aortic atherosclerosis than did control animals whose 11-wk high cholesterol diet was not supplemented with antioxidants (Fig. $1 \mathrm{~A}$ ). Moreover, the extent of atherosclerosis for 10 out of 11 animals in both the $\beta$-carotene and probucol-fed rabbits was less than the mean level for the control group ( $P<0.012$, assuming a binomial relation). In contrast, the groups supplemented with either vitamin E or 9cis $\beta$-carotene exhibited lesion development comparable to the control group. Similar results were obtained when lesion area was quantified in the aortic arch, thoracic aorta, and abdominal aorta (Table II).

Susceptibility of lipoproteins to oxidation ex vivo. Lipidsoluble antioxidants might prevent atherosclerosis by protecting LDL from oxidation. To investigate this possibility, LDL was isolated by sequential ultracentrifugation from plasma of the various groups of rabbits, and their resistance to stimulation of lipid peroxidation by the aqueous phase radical generator AAPH was determined. AAPH was used to measure the susceptibility of LDL to oxidation because it promotes lipid peroxidation by a well-understood mechanism (42). LDL isolated from probucol-fed rabbits was markedly resistant to oxidation (Fig. $1 \mathrm{~B}$ ).

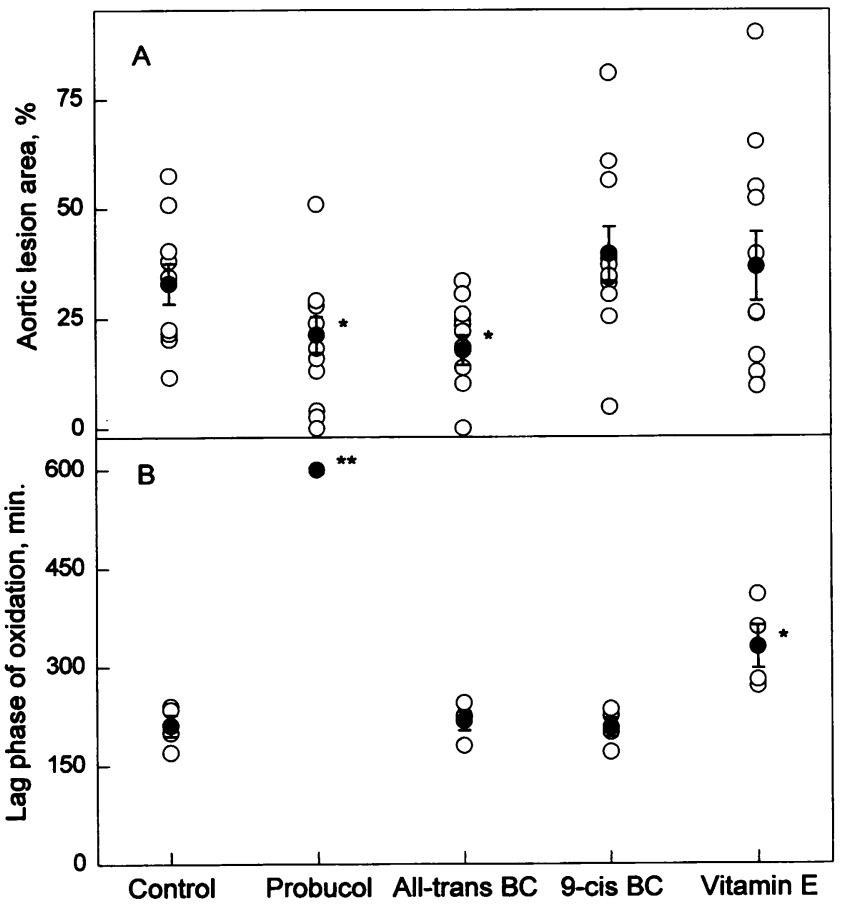

Figure 1. Extent of aortic atherosclerosis $(A)$ and susceptibility of LDL to oxidation ex vivo $(B)$ in groups of hypercholesterolemic rabbits treated with structurally unrelated antioxidants. Rabbits were fed $0.5 \%$ cholesterol diet (control animals) or high cholesterol diet supplemented with either $1 \%(\mathrm{wt} / \mathrm{wt}$ ) probucol, $0.01 \% \beta$-carotene $(B C)$ or $0.01 \%$ racemic vitamin $\mathrm{E}$. The extent of aortic atherosclerosis was quantified from digitized photographs ( 11 animals) and lipoproteins were isolated by ultracentrifugation ( 4 animals) after 11 and $8 \mathrm{wk}$ on the high cholesterol diets, respectively. LDL $(0.1 \mathrm{mg}$ protein $/ \mathrm{ml})$ was oxidized at $37^{\circ} \mathrm{C}$ in buffer $\mathrm{B}(150 \mathrm{mM} \mathrm{NaCl}, 200 \mu \mathrm{M}$ diethylenetriamine pentaacetic acid, $20 \mathrm{mM}$ sodium phosphate, $\mathrm{pH} 7.4$ ) containing $1 \mathrm{mM}$ AAPH. The lag phase for the onset of the propagation phase of lipid peroxidation was determined as described in Methods. The lag phase for probucol was $>600 \mathrm{~min}$. Results represent the mean \pm SEM. ${ }^{*} P<0.05 \mathrm{com}-$ pared to the control group. $* * P<0.005$ compared to the control group.

A small but significant degree of protection $(P<0.05)$ was observed for LDL isolated from the rabbits who received high levels of dietary vitamin $\mathrm{E}$.

In contrast to probucol and vitamin $\mathrm{E}$, supplemental $\beta$-carotene appeared to have no effect on lipoprotein oxidation ex vivo (Fig. $1 B$ ), indicating that the carotenoids were not protecting LDL from oxidation by either direct inhibition of lipid peroxidation or indirect effects such as changes in unsaturated fatty acid composition (43).

Both animal (18) and human studies (44) have suggested that there is a negative correlation between the lag phase for the onset of LDL lipid peroxidation ex vivo and the extent of atherosclerotic vascular disease. To determine whether a similar relationship existed in hypercholesterolemic rabbits treated with the various antioxidants, LDL isolated from the different groups of rabbits was exposed to AAPH for $4 \mathrm{~h}$, and the extent of lipid peroxidation was monitored as the content of cholesteryl ester hydroperoxides and thiobarbituric acid reacting substances (TBARS). For both methods, linear regression analysis revealed that the level of lipid peroxidation was highly correlated with the resistance of LDL to oxidation as monitored by the 
Table II. Extent of Atherosclerotic Lesions in Segments of Rabbit Aorta

\begin{tabular}{lccc}
\hline & \multicolumn{3}{c}{$\begin{array}{c}\text { Aortic atherosclerosis } \\
\text { (percent of surface area involved) }\end{array}$} \\
\cline { 2 - 4 } \multicolumn{1}{c}{ Group* } & Arch & Thoracic & Abdominal \\
\hline Control & $68.8 \pm 4.2$ & $24.6 \pm 4.5$ & $24.6 \pm 5.0$ \\
Probucol & $47.3 \pm 8.3^{\ddagger}$ & $15.2 \pm 5.1$ & $11.8 \pm 4.1^{\ddagger}$ \\
All-trans $\beta$-carotene & $42.5 \pm 7.0^{\ddagger}$ & $13.3 \pm 3.4^{\ddagger}$ & $14.5 \pm 3.1^{\ddagger}$ \\
9-cis $\beta$-carotene & $65.1 \pm 5.7$ & $34.7 \pm 6.1$ & $22.9 \pm 4.1$ \\
Vitamin E & $66.9 \pm 6.3$ & $31.5 \pm 9.0$ & $29.3 \pm 7.6$ \\
& & & \\
\hline
\end{tabular}

The extent of aortic atherosclerotic lesions was determined after $11 \mathrm{wk}$ of feeding rabbits the $0.5 \%$ cholesterol diet supplemented with the indicated antioxidants. The extent of aortic atherosclerosis is expressed as mean $( \pm$ SEM) percentage of total aortic surface area. $* 11$ animals per group; ${ }^{\ddagger} P<0.05$ compared to the control group.

duration of the lag phase $\left(\mathrm{R}_{\mathrm{CEOOH}}=0.87, P<0.001 ; \mathrm{R}_{\mathrm{TBARS}}\right.$ $=0.68, P<0.001)$. Importantly, there was no relationship between the susceptibility of lipoproteins to oxidation ex vivo, as monitored by either the lag phase or the two different assays for lipid peroxidation, and the extent of aortic atherosclerosis in the different groups of rabbits (Fig. 2).

Plasma and lipoprotein antioxidant concentrations. During the 2-wk standard diet, plasma $\alpha$-tocopherol concentration increased from $18 \pm 3 \mu \mathrm{M}$ to $37 \pm 9 \mu \mathrm{M}$ in the group supplemented with vitamin $E$; the probucol concentration increased from 0 to $89 \pm 15 \mu \mathrm{M}$ in the group supplemented with probucol. After 8 wk on the high cholesterol diet, levels of plasma $\alpha$-tocopherol were approximately threefold higher in the vitamin E-fed rabbits than in the control animals (Table III). Vitamin E levels in the other groups were not significantly different from those of control animals (Table III). Analysis of LDL, VLDL, and HDL isolated from plasma by ultracentrifugation showed that vitamin E likewise increased approximately threefold in each of the lipoprotein fractions (data not shown).

After 8 wk on the $0.5 \%$ cholesterol diet, probucol-fed rabbits exhibited high plasma concentrations of the drug (mean $=227 \pm 14 \mu \mathrm{M}$ ); as with vitamin $\mathrm{E}$, probucol accumulated in all lipoprotein fractions. It is noteworthy that probucol is metabolized to other products that have antioxidant activity in vitro and that these products also accumulate in plasma (45). The total antioxidant activity of plasma in probucol-fed rabbits is thus likely to be much higher than indicated by plasma levels of probucol alone. Indeed, certain metabolites are colored (45), and the plasma of probucol-treated animals exhibited a striking green hue.

In contrast to the other antioxidants, both isomers of $\beta$ carotene were undetectable (limit of sensitivity $<0.01 \mu \mathrm{M}$ ) throughout the study in both the plasma and lipoproteins of $\beta$ carotene-fed rabbits. Exogenously added $\beta$-carotene was readily detected in plasma, indicating that $\beta$-carotene degradation was not interfering with the assay.

Tissue antioxidant concentrations. The concentrations of probucol, vitamin $\mathrm{E}$, and $\beta$-carotene were measured in rabbit aortic tissue (Table IV) and liver. In control animals, the levels of vitamin $E$ in aortic arch and liver were $14.0 \pm 2.2$ and 8.3 \pm 3.5 nmol/gram, respectively. Animals fed vitamin $E$ underwent a threefold increase in tissue $\alpha$-tocopherol levels (aortic arch: $50.4 \pm 7.1 \mathrm{nmol} / \mathrm{gram}$; liver $23.2 \pm 6.9 \mathrm{nmol} / \mathrm{gram}$ ), but there was no significant decrease in the extent of atherosclerosis in this group (Fig. 1 and Table II). In probucol-fed rabbits, the concentration of probucol in aortic arch was 100-fold greater $(1,440 \pm 430 \mathrm{nmol} / \mathrm{gram})$ than the concentration of $\alpha$-tocopherol in the control animals (Table IV). Probucol was also present at high concentrations in liver $(197 \pm 57 \mathrm{nmol} /$ gram $)$.

In animals which had not received supplemental vitamin $\mathrm{E}$, a highly significant positive correlation $(r=0.75 ; P<0.001)$ was found by linear regression analysis between $\alpha$-tocopherol concentrations in aorta and the extent of lesion area. Vitamin $\mathrm{E}$ is a hydrophobic molecule which partitions into the lipid

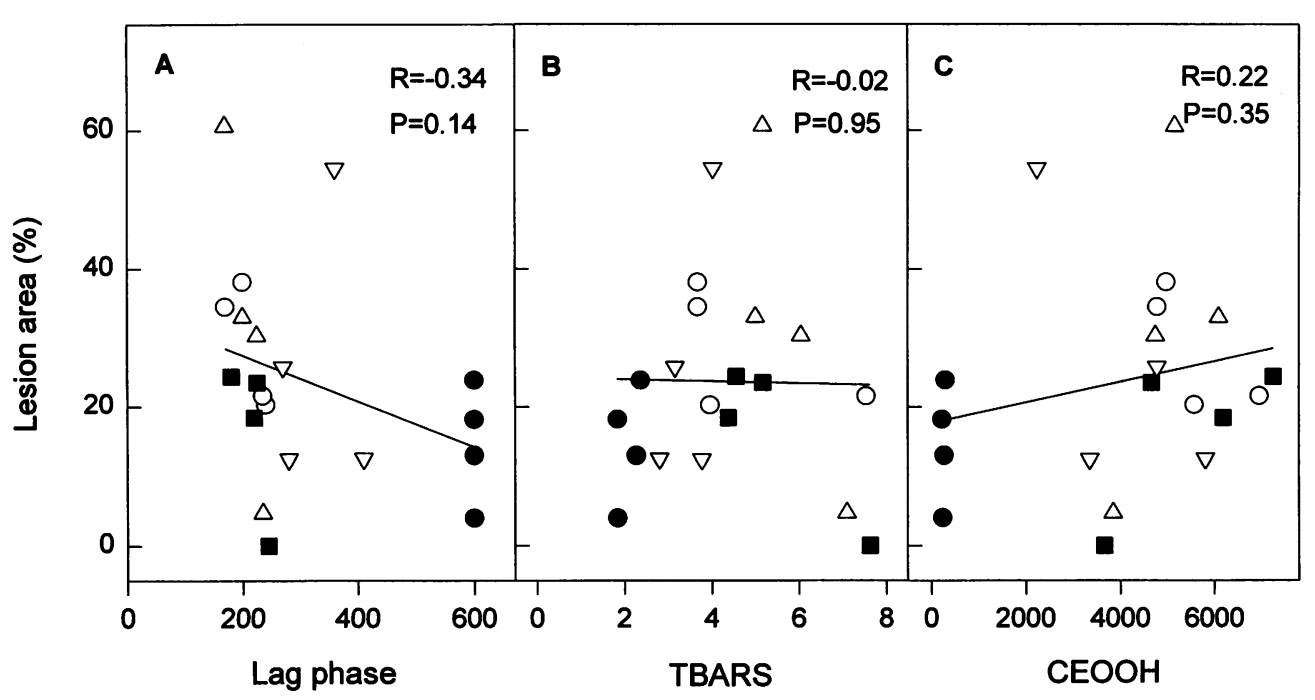

Figure 2. The extent of aortic atherosclerosis in hypercholesterolemic rabbits is unrelated to the protection of LDL from oxidation ex vivo. Rabbits were fed $0.5 \%$ cholesterol diet $(O$, control group $)$ or high cholesterol diet supplemented with the indicated antioxidant (๑, probucol; $\mathbf{\square}$, all-trans $\beta$ carotene; $\Delta, 9$-cis $\beta$-carotene; $\nabla$, vitamin $E$ ). The lag phase for LDL oxidation ex vivo $(A, \mathrm{~min})$ and the extent of aortic atherosclerosis were determined as described in the legend to Fig. 1. In a parallel set of experiments, LDL lipid peroxidation was measured as thiobarbituric reacting substances $(B, T B A R S$, nmol malondialdehyde equivalents/mg protein) and cholesteryl ester hydroperoxides $(C, C E O O H, \mathrm{nmol} / \mathrm{mg}$ protein) after a 4-h exposure to AAPH. 
Table III. Antioxidant Concentrations in Plasma

\begin{tabular}{llcc}
\hline & \multicolumn{3}{c}{ Plasma antioxidant levels $(\mu \mathrm{M})$} \\
\cline { 2 - 4 } \multicolumn{1}{c}{ Group } & $\alpha$-Tocopherol & Probucol & $\beta$-carotene \\
\hline Control & $25.0 \pm 6.0$ & 0 & $<0.01$ \\
Probucol & $20.2 \pm 0.9$ & $227 \pm 14^{\ddagger}$ & $<0.01$ \\
All-trans $\beta$-carotene & $19.1 \pm 4.5$ & 0 & $<0.01$ \\
9-cis $\beta$-carotene & $21.9 \pm 2.1$ & 0 & $<0.01$ \\
Vitamin E & $66.4 \pm 15.0^{*}$ & 0 & $<0.01$ \\
& & &
\end{tabular}

The concentrations of plasma antioxidants were determined by reverse phase HPLC analysis as described in Methods after $10 \mathrm{wk}$ of the high cholesterol diet. Results represent the mean \pm SEM of five animals for each group. ${ }^{*} P<0.05$ compared to the control group; ${ }^{\ddagger} P<0.005$ compared to the control group.

phase $(4,29,30)$, and aortic lipid content increases with increasing extent of atherosclerosis $(35,46)$. The strong association between $\alpha$-tocopherol levels and the extent of atherosclerosis presumably reflects partitioning of vitamin $\mathrm{E}$ into the lipids of vascular lesions. Aortic $\alpha$-tocopherol levels were significantly lower $(P<0.05)$ in the rabbits supplemented with either probucol or all-trans $\beta$-carotene than in the control animals (Table IV). These findings further support the notion that alltrans $\beta$-carotene inhibits lipid accumulation and lesion formation in cholesterol-fed rabbits.

To establish whether metabolites of $\beta$-carotene were being absorbed by the rabbits, tissue levels of retinyl palmitate were quantified. Concentrations of retinyl palmitate were significantly higher $(P<0.05)$ in the liver $(296 \pm 75 \mathrm{nmol} / \mathrm{gram})$ and aortic arch $(0.52 \pm 0.04 \mathrm{nmol} / \mathrm{gram})$ of all-trans $\beta$-carotenefed rabbits than in control rabbits $(218 \pm 34$ and $0.31 \pm 0.03$ $\mathrm{nmol} /$ gram, respectively). In contrast, there was no significant change in retinyl palmitate levels in either the liver or aortic arch of animals fed 9-cis $\beta$-carotene (Table IV). These results suggest that all-trans $\beta$-carotene was in part converted to retinol, which then accumulated in esterified form in tissue.

\section{Discussion}

Our results indicate that all-trans $\beta$-carotene inhibits atherosclerotic vascular disease in cholesterol-fed rabbits. It is generally believed that antioxidant vitamins prevent vascular disease in hypercholesterolemic animals by protecting LDL from oxidation. In contrast, we found that all-trans $\beta$-carotene inhibited atherosclerosis without affecting the susceptibility of LDL to oxidation ex vivo. The effects of all-trans $\beta$-carotene on atherosclerosis can thus be dissociated from the protection of LDL from oxidation, indicating that other mechanisms may account for the ability of this compound to prevent vascular disease.

One important issue is the relevance of the cholesterol-fed rabbit as a model for the pathogenesis of human atherosclerosis. LDL is a major risk factor for atherosclerosis and many lines of evidence suggest that it must be oxidized to promote vascular wall disease (5-19). In contrast, $\beta$-VLDL is the major circulating lipoprotein in rabbits fed high cholesterol diets (47). The role of oxidation in atherogenesis induced by $\beta$-VLDL is uncertain because $\beta$-VLDL itself converts cultured macrophages into foam cells (48). Despite these differences, three lines of evi-
Table IV. Levels of $\alpha$-Tocopherol, Probucol, and Retinyl Palmitate in Aortic Arch of Control and Antioxidant-treated Rabbits

\begin{tabular}{lccc}
\hline \multirow{2}{*}{\multicolumn{1}{c}{ Group }} & \multicolumn{3}{c}{ Aortic arch antioxidant levels (nmol/gram) } \\
\cline { 2 - 4 } & $\alpha$-Tocopherol & Probucol & Retinyl palmitate \\
\hline Control & $14.0 \pm 2.2$ & 0 & $0.31 \pm 0.03$ \\
Probucol & $8.3 \pm 0.9^{*}$ & $1440 \pm 430^{\ddagger}$ & $0.30 \pm 0.03$ \\
All-trans $\beta$-carotene & $9.4 \pm 1.8^{*}$ & 0 & $0.52 \pm 0.04^{*}$ \\
9-cis $\beta$-carotene & $11.9 \pm 3.5$ & 0 & $0.37 \pm 0.05$ \\
Vitamin E & $50.4 \pm 7.1^{*}$ & 0 & $0.32 \pm 0.03$ \\
& & & \\
\hline
\end{tabular}

The animals were killed after $11 \mathrm{wk}$ of the high cholesterol diet and the concentrations of tissue antioxidants determined by reverse phase HPLC analysis as described in Methods. Results represent the mean \pm SEM of five animals for each group. ${ }^{*} P<0.05$ compared to the control group; ${ }^{\ddagger} P<0.005$ compared to the control group.

dence suggest that the cholesterol-fed rabbit is a useful model for studying atherogenesis. First, in rabbits fed a $0.5 \%$ cholesterol diet, the level used in our studies, the majority of cholesterol is present in $\operatorname{LDL}(47,49)$. In contrast, large amounts of $\beta$-VLDL are found in rabbits receiving a $2 \%$ cholesterol diet (47). Second, the differences in distribution of cholesterol among lipoproteins in cholesterol-fed and LDL receptor-deficient rabbits does not influence the pathological features of atherosclerotic lesions (50). Moreover, the cellular response of the artery wall in hypercholesterolemic rabbits strongly resembles that observed in the early and intermediate stages of human atherosclerosis $(50,51)$. Third, atherosclerosis in cholesterolfed rabbits is inhibited by both probucol $(35,52)$ and $N, N^{\prime}$ diphenyl-phenylenediamine (17), which implies that lipoproteins are exerting atherogenic events that might be influenced by lipid soluble antioxidants (53). It should be noted that there is no direct evidence implicating LDL oxidation in human atherogenesis. Studies examining LDL-like lipoproteins isolated from human atherosclerotic lesions have reached differing conclusions regarding its state of oxidation and its ability to be taken up by the macrophage scavenger receptor $(13,54)$

We were unable to detect $\beta$-carotene in the plasma and lipoproteins of the $\beta$-carotene-treated animals, and LDL isolated from the $\beta$-carotene-treated animals was oxidized ex vivo at the same rate as LDL isolated from control animals. Thus, $\beta$-carotene or its metabolites were not protecting LDL from oxidation either directly, by acting as a lipid-soluble antioxidant $(19,23,24)$, or indirectly, for example by changing the unsaturated fatty acid composition of LDL (43). The failure to detect $\beta$-carotene in rabbit plasma reflects an important metabolic difference between humans and rabbits. In humans, a significant fraction of $\beta$-carotene is absorbed from the intestine and is then converted to metabolites in the liver and peripheral tissues (55). In contrast, in most other species the intestinal epithelium rapidly cleaves $\beta$-carotene to retinoic acid, retinal and other products $(24,55,56)$ and little $\beta$-carotene is absorbed intact. Retinal is reduced to retinol for transport in plasma and converted to retinyl palmitate by tissues (55). We found that retinyl palmitate levels were elevated in the livers and aortae of the all-trans $\beta$-carotene-treated animals, but not in the 9-cis $\beta$-carotenetreated animals. Previous studies have shown that aortic levels of $\beta$-carotene (57), as well as plasma levels of retinoic acid 
(56), increase significantly in rabbits fed $\beta$-carotene. These results indicate that both tissue and plasma levels of carotenoids increase in rabbits fed all-trans $\beta$-carotene.

A key question raised by our studies is the mechanism(s) by which all-trans $\beta$-carotene protects against atherosclerotic vascular disease. Jialal et al. showed that $\beta$-carotene inhibited LDL oxidation induced by cultured macrophages, and suggested that the compound acts as an antioxidant (25). However, other studies have failed to demonstrate that $\beta$-carotene protects LDL from oxidation $(26,27,57)$. Navab et al. found that pretreatment of cocultures of smooth muscle cells and endothelial cells with $\beta$-carotene, but not incubation of LDL itself with $\beta$-carotene, prevents the conversion of LDL to an atherogenic particle, suggesting that $\beta$-carotene or one of its metabolites inhibits the generation of oxidizing intermediates by cells (58). Probucol might exert similar effects in vivo because a water soluble analogue of probucol reduces the capacity of cells to oxidize LDL in vitro (59). Another potential target for regulation by $\beta$-carotene is endothelium-dependent vessel relaxation, which becomes abnormal early in atherogenesis (57). Keaney et al. demonstrated that both $\beta$-carotene and vitamin $E$ preserved endothelium-dependent relaxation in hypercholesterolemic rabbits, but that only the LDL from the vitamin E-treated animals demonstrated increased resistance to oxidation ex vivo (57). They suggested that inhibition of atherosclerosis may relate to levels of antioxidants in vascular tissue, and that the resistance of LDL to oxidation ex vivo was a poor predictor of protection against oxidative damage in vivo.

It is of interest that all-trans $\beta$-carotene, but not 9-cis $\beta$ carotene, reduced lesion formation in hypercholesterolemic rabbits. $\beta$-carotene is metabolized to retinoids $(55,56)$, which exert powerful effects on growth and differentiation via their interactions with two families of nuclear transcription factors, the retinoic acid receptors and the retinoid $X$ receptors $(60$, 61 ). The retinoic acid receptor is activated by both all-trans retinoic acid and 9-cis retinoic acid, whereas the retinoid $\mathrm{X}$ receptor is selectively activated by 9 -cis retinoic acid (61), raising the possibility that genes specifically controlled by the retinoic acid receptor may inhibit atherosclerosis. Retinoic acid regulates the expression in cultured cells of several proteins implicated in atherogenesis, including thrombomodulin (62) and monocyte chemoattractant protein-1 (63).

We have confirmed that LDL isolated from probucol-treated rabbits is markedly resistant to oxidation, and that probucol inhibits atherosclerosis, which supports the hypothesis that this compound is acting as a lipid-soluble antioxidant $(5,6,19)$. However, probucol exerts other biological effects which may be anti-atherogenic, including lowering of plasma cholesterol $(5,6)$, stimulation of monocyte chemotaxis $(21)$, and modulation of the physical state of cellular cholesteryl esters (64). Probucol was given at very high levels in the diet (1\% by weight) and the concentrations of probucol in plasma and tissue were 10- and 100-fold greater, respectively, than those of endogenous vitamin $E$. The relevance of such dietary and tissue antioxidant levels to the prevention of human atherosclerosis is uncertain. Indeed, a recent study showed that lower levels of dietary probucol did not inhibit atherosclerosis in hypercholesterolemic rabbits despite significantly protecting LDL from oxidation ex vivo (65).

Vitamin $\mathrm{E}$ behaved differently from all-trans $\beta$-carotene and probucol. Its level increased threefold in both plasma and tissue in the vitamin E-treated animals, and this was associated with a small but significant degree of protection of LDL from oxidation. Similar increases in the vitamin E content of LDL and resistance of LDL to oxidation ex vivo have recently been reported in humans using supplemental vitamin E $(26,27)$. There was no evidence that the development of atherosclerosis was inhibited in the vitamin E-fed rabbits. However, there was marked variability in the extent of atherosclerosis in this group of rabbits, which may have obscured a biologically significant effect of the vitamin. Thus, further studies will be necessary to address conclusively the role of vitamin $E$ in preventing vascular disease in hypercholesterolemic animal models.

Two double-blind, placebo-controlled interventional trials, the best test of the therapeutic effectiveness of vitamin supplementation, have examined the role of $\beta$-carotene in the prevention of human vascular disease. In the Physician's Health Study, male physicians were assigned to aspirin and $\beta$-carotene therapy. A preliminary report of subgroup analysis of doctors with a history of coronary artery disease revealed that $\beta$-carotene treatment resulted in a 50\% reduction in the risk of major cardiovascular events $(1,66)$. The effect of intervention was time dependent, suggesting that $\beta$-carotene was slowing the progression of vascular disease. The primary endpoint in the AlphaTocopherol Beta-Carotene Cancer Prevention Study was the risk for lung cancer in male smokers taking supplemental $\beta$ carotene and vitamin $E$; the incidence of coronary artery disease was also monitored (31). This study failed to demonstrate that the incidence of ischemic heart disease was reduced by either $\beta$-carotene or vitamin E. However, smoking may represent such a powerful risk factor for atherosclerosis that beneficial effects of vitamin therapy were not observed. Further interventional studies will be necessary to evaluate the relevance of our findings to the efficacy of $\beta$-carotene and vitamin $E$ in the prevention of atherosclerosis.

Our results suggest that carotenoids derived from all-trans $\beta$-carotene block atherosclerosis in cholesterol-fed rabbits by novel pathways independent of making LDL resistant to oxidation. The identification of the mechanism(s) by which all-trans $\beta$-carotene protects against vascular disease may provide rational targets for the design of specific interventions and provide further insights into the nature of the as yet unknown events that transform healthy arterial wall cells into the precursors of life-threatening atherosclerotic lesions.

\section{Acknowledgments}

We thank Drs. L. Sage, S. L. Hazen, and J. S. Jacob for critical reading of the manuscript and L. Rachel, T. Kitchens, and D. M. Mueller for excellent technical assistance.

This work was supported by Grant-In-Aids (A. Daugherty and J. W. Heinecke) from the American Heart Association and grants RO1 CA57903, RO3 AA09988, and RO1 AG12293 from the National Institutes of Health. A. Daugherty and J. W. Heinecke are Established Investigators of the American Heart Association.

\section{References}

1. Gaziano, J. M., and C. H. Hennekens. 1993. The role of beta-carotene in the prevention of cardiovascular disease. In Carotenoids in Human Health. L. M. Canfield, N. I. Krinsky, J. A. Olson, editors. New York Academy of Sciences, New York. 148-155.

2. Gey, K. F., P. Puska, P. Jordan, and U. K. Moser. 1991. Inverse correlation between plasma vitamin $\mathrm{E}$ and mortality from ischemic heart disease in crosscultural epidemiology. Am. J. Clin. Nutr. 52:3265-3345.

3. Stampfer, M. J., C. H. Hennekens, J. E. Manson, G. A. Colditz, B. Rosner, 
and W. C. Willett. 1993. Vitamin E consumption and the risk of coronary disease in women. N. Engl. J. Med. 328:1444-1449.

4. Bjornson, L. K., H. J. Kayden, E. Millen, and A. N. Moshell. 1976. The transport of alpha-tocopherol and beta-carotene in human blood. J. Lipid Res. $17: 343-352$

5. Kita, T., Y. Nagano, M. Yokode, K. Ishi, N. Kume, S. Ooshima, H. Yoshida and C. Sawai. 1987. Probucol prevents the progression of atherosclerosis in Watanabe heritable hyperlipidemic rabbit, an animal model for familial hypercholesterolemia. Proc. Natl. Acad. Sci. USA. 84:5928-5931.

6. Carew, T. E., D. C. Schwenke, and D. Steinberg. 1987. Antiatherogenic effect of probucol unrelated to its hypercholesterolemic effect: evidence that antioxidants in vivo can selectively inhibit low density lipoprotein degradation in macrophage-rich fatty streaks and slow the progression of atherosclerosis in the Watanabe heritable hyperlipidemic rabbit. Proc. Natl. Acad. Sci. USA. 84:77257729.

7. Heinecke, J. W., H. Rosen, and A. Chait. 1984. Iron and copper promote modification of low density lipoprotein by human arterial smooth muscle cells in culture. J. Clin. Invest. 74:1890-1894.

8. Morel, D. W., P. E. DiCorleto, and G. M. Chisolm. 1984. Endothelial and smooth muscle cells alter low density lipoprotein in vitro by free radical oxidation. Arteriosclerosis. 4:357-364.

9. Steinbrecher, U. P., S. Parthasarathy, D. S. Leake, J. L. Witztum, and D. Steinberg. 1984. Modification of low density lipoprotein by endothelial cells involves lipid peroxidation and degradation of low density lipoprotein phospholipids. Proc. Natl. Acad. Sci. USA. 81:3883-3887.

10. Henriksen, T., E. M. Mahoney, and D. Steinberg. 1981. Enhanced macrophage degradation of low density lipoprotein previously incubated with cultured endothelial cells: recognition by receptors for acetylated low density lipoproteins. Proc. Natl. Acad. Sci. USA. 78:6499-6503.

11. Berliner, J. A., M. C. Territo, A. Sevanian, S. Ramin, J. A. Kim, B Bamshad, M. Esterson, and A. M. Fogelman. 1990. Formally modified low density lipoprotein stimulates monocyte endothelial interactions. J. Clin. Invest. 85:12601266

12. Daugherty, A., B. S. Zweifel, B. E. Sobel, and G. Schonfeld. 1988 Isolation of low density lipoprotein from atherosclerotic vascular tissue of Watanabe heritable hyperlipidemic rabbits. Arteriosclerosis. 8:768-777.

13. Palinski, W., M. E. Rosenfeld, S. Yla-Hertulla, G. C. Gurtner, S. S. Socher S. W. Butler, S. Parthasarathy, T. E. Carew, D. Steinberg, and J. L. Witztum. 1989. Low density lipoprotein undergoes oxidative modification in vivo. Proc Natl. Acad Sci. USA 86:1372-1376.

14. Haberland, M. E., D. Fong, and L. Cheng. 1988. Malondialdehyde-altered protein occurs in atheroma of Watanabe heritable hyperlipidemic rabbits. Science (Wash. DC). 241:215-218.

15. Bjorkhem, I., A. Henrikson-Freyschuss, O. Breuer, U. Dcezfalusy, L. Berglund, and P. Henriksson. 1991. The antioxidant butylated hydroxytoluene protects against atherosclerosis. Arterioscler. Thromb. 11:15-22.

16. Mao, S. T. J., M. T. Yates, R. A. Parker, E. M. Chi, and R. L. Jackson 1991. Attenuation of atherosclerosis in a modified strain of hypercholesterolemic Watanabe rabbits with use of a probucol analogue (MDL 29,311) that does no lower serum cholesterol. Arterioscler. Thromb. 11:1266-1275.

17. Sparrow, C. P., T. W. Doebber, J. Olszewski, M. S. Wu, J. Ventre, K. A. Stevens, and Y. S. Chao. 1992. Low density lipoprotein is protected from oxidation and the progression of atherosclerosis is slowed in cholesterol-fed rabbits by the antioxidant $N, N^{\prime}$-diphenyl-phenylenediamine. J. Clin. Invest. 89:1885-1891.

18. Sasahara, M., E. W. Raines, A. Chait, T. E. Carew, D. Steinberg, P. W. Wahl, and R. Ross. 1994. Inhibition of hypercholesterolemia-induced atherosclerosis in nonhuman primate by Probucol. I. Is the extent of atherosclerosis related to resistance of LDL to oxidation? $J$. Clin. Invest 94:155-164.

19. Parthasarathy, S., S. G. Young, J. L. Witztum, R. C. Pittman, and D. Steinberg. 1986. Probucol inhibits oxidative modification of low density lipoprotein. J. Clin. Invest. 77:641-644.

20. Fruebis, J., D. Steinberg, H. A. Dresel, and T. E. Carew. 1994. A comparison of the antiatherogenic effects of probucol and of a structural analogue of probucol in low density lipoprotein receptor-deficient rabbits. J. Clin. Invest. 94:392-398.

21. Hara, S., Y. Nagano, M. Sasada, and T. Kita. 1992. Probucol pretreatment enhances the chemotaxis of mouse peritoneal macrophages. Arterioscler. Thromb 12:593-600.

22. O'Brien, K., Y. Nagano, A. Gown, T. Kita, and A. Chait. 1991. Probuco treatment affects the cellular composition but not anti-oxidized low density lipoprotein immunoreactivity of plaques from Watanabe heritable hyperlipidemic rabbits. Arterioscler. Thromb. 11:751-759.

23. Burton, G. W., and K. U. Ingold. 1984. Beta-carotene: an unusual type of lipid antioxidant. Science (Wash. DC). 224:569-573.

24. Palozza, P., and N. I. Krinsky. 1992. Antioxidant effects of carotenoids in vivo and in vitro: an overview. Methods Enzymol. 213:403-429.

25. Jialal, I., E. P. Norkus, L. Cristol, and S. M. Grundy, 1991. Beta-carotene inhibits the oxidative modification of low-density lipoprotein. Biochim. Biophys. Acta. 1086:134-138.

26. Princen, H. M. G., G. V. Poppel, C. Vogelezang, R. Buytenhek, and F. J.
Kok. 1992. Supplementation with vitamin $E$ but not beta-carotene in vivo protects low density lipoprotein from lipid peroxidation in vitro. Effect of cigarette smoking. Arterioscler. Thromb. 12:554-562.

27. Reaven, P. D., A. Khouw, W. F. Beltz, S. Parthasarathy, and J. L. Witztum 1993. Effect of dietary antioxidant combinations in humans protection of LDL by vitamin $\mathrm{E}$ but not by beta-carotene. Arterioscler. Thromb. 13:590-600.

28. Lavy, A., A. Ben-Amotz, and M. Aviram. 1993. Preferential inhibition of LDL oxidation by the all-trans isomer of beta-carotene in comparison with 9-cis beta-carotene. Eur. J. Clin. Biochem. 31:83-90.

29. Esterbauer, H., G. Jurgens, O. Quehenberger, and E. Koller. 1987. Autoxidation of human low density lipoprotein: loss of polyunsaturated fatty acids and vitamin E and generation of aldehydes. J. Lipid Res. 28:495-509.

30. Bowery, V. W., and R. Stocker. 1993. Tocopherol-mediated peroxidation. The prooxidant effect of vitamin $\mathrm{E}$ on the radical-initiated oxidation of human low-density lipoprotein. J. Am. Chem. Soc. 115:6029-6044.

31. The alpha-tocopherol, beta-carotene and cancer prevention study group. 1994. The effect of vitamin $E$ and beta-carotene on the incidence of lung cance and other cancers in male smokers. N. Engl. J. Med. 330:1029-1035.

32. Lynch, S. M., and B. Frei. 1994. Animal studies. In Natural Antioxidants in Human Health and Disease. B. Frei, editor. Academic Press, Inc., Orlando, FL. 353-386.

33. Daugherty, A., and S. E. Roselaar. 1995. Lipoprotein oxidation as a mediator of atherogenesis: insights from pharmacological studies. Cardiovasc. Res. 29:297-311.

34. Ben-Amotz, A., A. Lers, and M. Avron. 1988. Steoisomers of beta-carotene and phytoene in the alga Dunaliella bardawil. Plant Physiol. (Bethesda). 86:1286-1291.

35. Daugherty, A., B. S. Zweifel, and G. Schonfeld. 1991. The effect of probucol on the progression of atherosclerosis in mature Watanabe heritable hyperlipidaemic rabbits. Br. J. Pharmacol. 103:1013-1018.

36. Shaish, A., A. Ben-Amotz, and M. Avron. 1992. Biosynthesis of betacarotene in Dunaliella. Methods Enzymol. 213:439-444.

37. Esterbauer, H., G. Striegl, P. Puhl, and M. F. Rotheneder. 1989. Continuous monitoring of in vitro oxidation of human low density lipoprotein. Free Rad. Res. Commun. 6:67-75

38. Heinecke, J. W., L. Baker, H. Rosen, and A. Chait. 1986. Superoxidemediated modification of low density lipoprotein by human arterial smooth muscle cells in culture. J. Clin. Invest. 77:757-761.

39. Savenkova, M., D. M. Mueller, and J. W. Heinecke. 1994. Tyrosyl radical generated by myeloperoxidase is a physiological catalyst for the initiation of lipid peroxidation in low density lipoprotein. J. Biol. Chem. 269:20394-20400.

40. Miller, R. G. 1986. Beyond ANOVA: Basics of Applied Statistics. J. Wiley \& Sons, Inc., New York.

41. Efron, B., and B. Tibshirani. 1993. An Introduction to the Bootstrap Chapman \& Hall, New York.

42. Niki, E., Y. Yamamoto, E. Komuro, and K. Sato. 1991. Membrane damage due to lipid oxidation. Am. J. Clin. Nutr. 53(Suppl.):201S-205S.

43. Thomas, M. J., T. Thornburg, J. Manning, K. Hooper, and L. R. Lawrence. 1994. Fatty acid composition of low-density lipoprotein influences its susceptibility to autoxidation. Biochemistry. 33:1828-1834.

44. Regnström J., J. Nilsoon, P. Tornvall, C. Landou, and A. Hamsten. 1992. Susceptibility to low-density lipoprotein oxidation and coronary atherosclerosis in man. Lancet. 339:1183-1186.

45. Barnhart, R. L., S. J. Busch, and R. L. Jackson. 1989. Concentrationdependent antioxidant activity of probucol in low density lipoproteins in vitro: probucol degradation precedes lipoprotein oxidation. J. Lipid Res. 30:1703-1710.

46. Small, D. M. 1988. Progression and regression of atherosclerotic lesions. Arteriosclerosis. 8:103-129.

47. Bocan, T. M. A., S. B. Mueller, M. J. Mazur, P. D. Uhlendorf, E. Q Brown, and K. A. Kieft. 1993. The relationship between the degree of dietaryinduced hypercholesterolemia in the rabbit and atherosclerotic lesion formation. Atherosclerosis. 102:9-22.

48. Mahley, R. W. 1983. Development of accelerated atherosclerosis: concepts derived from cell biology and animal models. Arch. Pathol. Lab. Med. 107:393 399.

49. Daugherty, A., and D. L. Rateri. 1994. Presence of LDL receptor-related protein/alpha2-macroglobulin receptors in macrophages of atherosclerotic lesion from cholesterol-fed New Zealand and heterozygous Watanabe heritable hyperlipidemic rabbits. Arterioscler. Thromb. 14:2017-2024.

50. Rosenfeld, M. E., A. Chait, E. L. Bierman, W. King, P. Goodwin, C. E. Walden, and R. Ross. 1988. Lipid composition of aorta of Watanabe heritable hyperlipidemic and comparably hypercholesterolemic fat-fed rabbits. Arteriosclerosis. 8:338-347.

51. Stary, H. C., D. H. Blankenhorn, B. Chandler, S. Glagov, W. Insull, Jr. M. Richardson, M. E. Rosenfeld, E. A. Schaffer, C. J. Schwartz, W. D. Wagner, and R. W. Whissler. 1992. A definition of the intima of human arteries and its atherosclerosis-prone regions. Arterioscler. Thromb. 12:120-134.

52. Daugherty, A., B. S. Zweifel, and G. Schonfeld. 1989. Probucol attenuates the development of aortic atherosclerosis in cholesterol-fed rabbits. Br. J. Pharma col. 98:612-618. 
53. Witztum, J. L., and D. Steinberg. 1991. Role of oxidized low density lipoprotein in atherogenesis. J. Clin. Invest. 88:1785-1792.

54. Steinbrecher, U. P., and M. Lougheed. 1992. Scavenger receptor-independent stimulation of cholesterol esterification in macrophages by low density lipoprotein extracted from human aortic intima. Arterioscler. Thromb. 12:608-625.

55. Blomhoff, R., M. H. Green, T. Berg, and K. R. Norum. 1990. Transport and storage of vitamin A. Science (Wash. DC). 250:399-404.

56. Folman, Y., R. M. Russell, G. W. Tang, and G. Wolf. 1989. Rabbits fed beta-carotene have higher serum levels of all-trans retinoic acid than those receiving no beta-carotene. Br. J. Nutr. 62:195-201.

57. Keaney, J. F., Jr., J. M. Gaziano, A. Xu, B. Frei, J. Curran-Celentano, G. T. Shwaery, J. Loscalzo, and J. A. Vita. 1993. Dietary antioxidants preserve endothelium-dependent vessel relaxation in cholesterol-fed rabbits. Proc. Natl. Acad. Sci. USA. 90:11880-11884.

58. Navab, M., S. S. Imes, S. Y. Hama, G. P. Hough, L. A. Ross, R. W. Bork A. J. Valente, J. A. Berliner, D. C. Drinkwater, H. Laks, and A. M. Fogelman. 1991. Monocyte transmigration induced by modification of low density lipoprotein in cocultures of human aortic wall cells is due to induction of monocytes chemotactic protein 1 synthesis and is abolished by high density lipoprotein. J. Clin. Invest. 88:2039-2046.

59. Parthasarathy, S. 1992. Evidence for an additional intracellular site of action of probucol in the prevention of oxidative modification of low density lipoprotein. Use of a new water-soluble probucol derivative. J. Clin. Invest. 89:1618-1621.

60. Mangelsdorf, D. J., S. A. Kliewer, A. Kakizuka, K. Umesono, and R. M. Evans. 1993. Retinoid receptor. Recent Prog. Horm. Res. 48:99-121.

61. Leid, M., P. Kastner, and P. Chambon. 1992. Multiplicity generates diversity in the retinoic acid signalling pathways. Trends Biochem Sci. 17:427-433.

62. Ishii, H., S. Horie, K. Kizaki, and M. Kazama. 1992. Retinoic acid counteracts both the downregulation of thrombomodulin and the induction of tissue factor in cultured human endothelial cells exposed to tumor necrosis factor. Blood. $80: 2556-2562$.

63. Burn, T. C., M. S. Provick, S. H. Hohaus, B. J. Rollins, and D. G. Tenen. 1994. Monocyte chemoattractant protein-1 is expressed in activated neutrophils and retinoic acid-induced human myeloid cell lines. Blood. 84:2776-2782.

64. McLean, L. R., C. E. Thomas, B. Weintraub, and K. A. Hagaman. 1992 Modulation of the physical state of cellular cholesteryl esters by probucol. $J$. Biol. Chem. 267:12291-12298.

65. Kleinveld, H. A., P. N. Demacker M., and A. F. H. Stalenhoef. 1994 Comparative study on the effect of low dose vitamin $\mathrm{E}$ and probucol on the susceptibility of LDL to oxidation and the progression of atherosclerosis in Watanabe heritable hyperlipidemic rabbits. Arterioscler. Thromb. 14:1386-1391.

66. Gaziano, J. M., J. E. Manson, P. M. Ridker, J. E. Buring, and C. H. Hennekens. 1990. Beta carotene therapy for chronic stable angina. Circulation. 82(Suppl. III):202 